\title{
Antifouling Lipid Membranes over Protein A for Orientation- Controlled Immunosensing in Undiluted Serum and Plasma
}

\author{
Kristy S. McKeating ${ }^{\dagger, \perp}$, Samuel S. Hinman ${ }^{\ddagger}, \#$, Nor Akmaliza Rais ${ }^{\S}$, Zhiguo Zhou ${ }^{\| l, \nabla}$, Quan \\ Cheng ${ }^{*}, \dagger, \ddagger$ \\ †Department of Chemistry, University of California, Riverside, Riverside, California 92521, United \\ States \\ ‡Environmental Toxicology, University of California, Riverside, Riverside, California 92521, United \\ States \\ §Department of Chemical and Environmental Engineering, University of California, Riverside, \\ Riverside, California 92521, United States \\ "Luna Innovations Inc., Danville, Virginia 24541, United States
}

\begin{abstract}
An important advance in biosensor research is the extension and application of laboratorydeveloped methodologies toward clinical diagnostics, though the propensity toward nonspecific binding of materials in clinically relevant matrices, such as human blood serum and plasma, frequently leads to compromised assays. Several surface chemistries have been developed to minimize nonspecific interactions of proteins and other biological components found within blood and serum samples, though these often exhibit substantially variable outcomes. Herein we report a surface chemistry consisting of a charged-matched supported lipid membrane that has been tailored to form over a gold surface functionalized with protein A. Fine tuning of the interfacial charge of this membrane, along with rational selection of a backfilling self-assembled monolayer, allows for high surface coverage with retention of orientation-controlled capture antibody attachment. We demonstrate using surface-plasmon resonance (SPR) that this highly charged lipid membrane is antifouling, allowing for complete removal of nonspecific human serum and plasma components using only a mild buffer rinse, which we attribute to unique steric interactions with the underlying surface. Furthermore, this surface chemistry is successfully applied for specific detection of IgG and cholera toxin in undiluted human biofluids with negligible sacrifice of SPR
\end{abstract}

\footnotetext{
*Corresponding Author quan.cheng@ucr.edu. Tel.: (951) 827-2702. Fax: (951) 827-4713.

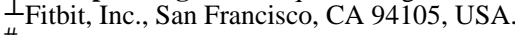

\#Department of Chemistry, University of North Carolina at Chapel Hill, Chapel Hill, NC 27599, USA.

$\nabla_{\text {Zymeron Corp., }} 400$ Park Offices Dr., Research Triangle Park, NC 27709, USA.

ASSOCIATED CONTENT

Supporting Information

The Supporting Information is available free of charge on the ACS Publications website at DOI: 10.1021/acssensors.9b00257. Additional experimental details including surface and gold nanoparticle conjugation strategies; sensorgrams of extended wash experiment, mixed membrane composition, POPG membrane deposition, membranes formed over silica, concentration of protein A, choice of spacer molecule, and IgG analysis, and nanoparticle-enhanced detection of CT (Figures S1-S6, S8, and S12), FRAP analysis (Figure S7), comparisons of IgG detection and of antibody attachment methods (Figures S9 and S10), concentration dependent CT signals (Figure S11) (PDF)

The authors declare no competing financial interest.
} 
signal compared to buffered analysis. This novel lipid membrane interface over protein A may open new avenues for direct biosensing of disease markers within clinical samples.

\section{Graphical Abstract}

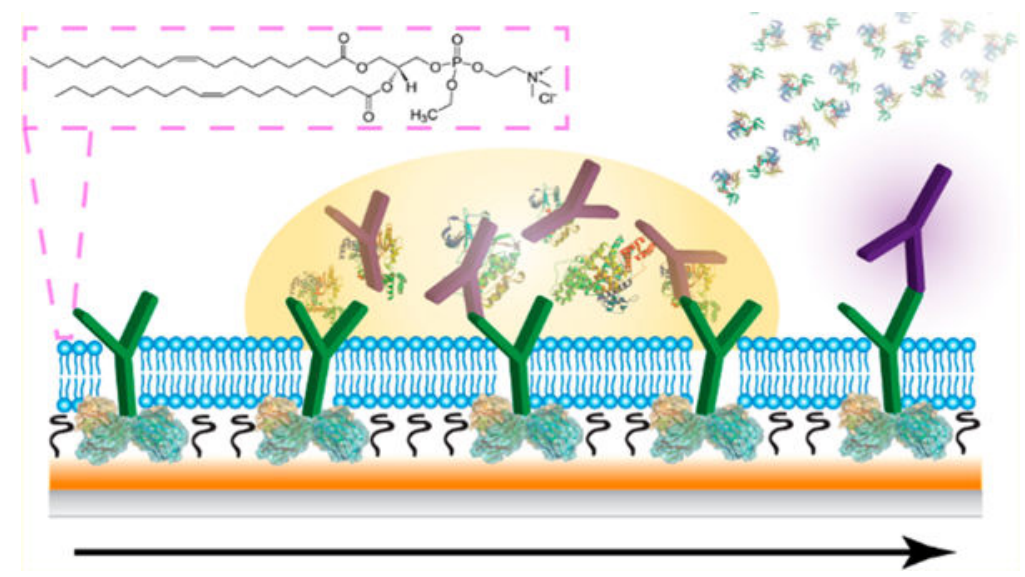

\section{Keywords}

antifouling; lipid membrane; surface-plasmon resonance; biosensing; human biofluid

Direct biomarker analysis within blood and serum holds great promise for monitoring of patient homeostasis, disease state, and drug or environmental exposure, provided that it can be performed in a sensitive, reproducible, and efficient fashion. ${ }^{1}$ With careful antibody selection and validation, immunoaffinity assays have remained the top choice for specific detection of a multitude of analytes, though their performance within complex, clinically relevant matrices can be fraught with issues. The nonspecific accumulation of molecules from these environments onto sensor surfaces is a problem that plagues this suite of platforms, and constitutes one of the biggest limitations from obtaining accurate measurements within clinical environments. As such, a plethora of methodologies intended to minimize these nonspecific interactions and resulting background signals have undergone aggressive development. ${ }^{2,3}$ Sample dilution may be performed to minimize the concentration of nontarget molecules, though this strategy correspondingly minimizes target concentration and is not always practical. ${ }^{4}$ Surface blocking with adsorbed, nonreactive compounds (e.g., bovine serum albumin, Tween-20, and commercially available mixtures) has seen many notable successes for a variety of clinical targets within human bodily fluids. ${ }^{5-9}$ Integrated chemical derivatization strategies may reduce assay time further through elimination of these blocking steps and have included the use of polysaccharides (e.g., carboxymethylated dextran), ${ }^{3,10}$ polymeric monolayers (e.g., poly(ethylene glycol)), ${ }^{2,3,11}$ peptides, ${ }^{12}$ ionic liquids, ${ }^{13}$ and zwitterionic compounds. ${ }^{14,15}$ The latter category spans a wide variety of molecules, though phosphocholine based interfaces have demonstrated particularly notable successes in reducing nonspecific adsorption onto glass and gold surfaces. ${ }^{15-18}$ As a major component of the eukaryotic cellular membrane, this surface moiety is not only capable of mimicking this biological environment, but is remarkably resistant against fouling from extracellular constituents. ${ }^{15,18}$ 
The choice of antibody immobilization strategy can also lead to substantially variable performance outcomes and must be carefully tailored for each assay. When a capture antibody is bound to a surface by electrostatic adsorption or covalent cross-linking (e.g., using EDC/NHS, SMCC, and $\mathrm{BS}^{3}$, etc.), as is common practice, the attachment efficiency and orientation are dependent upon accessible functional groups and localized areas of charge on the antibody surface, which are highly variable. Moreover, hydrolytic reactions often act in competition with succinimidyl ester based covalent attachment schemes, complicating situations where antibody stability is sensitive to $\mathrm{pH} .{ }^{19}$ In a nonideal scenario, the antibody of interest may be attached with the fragment antigen-binding (Fab) region unexposed, or in the worst case, not attached at all, rendering the constructed sensor incapable of measuring its intended target. Oriented immobilization of antibodies to a sensor surface can be universally achieved through the use of proteins with $\mathrm{Fc}$ (fragment crystallizable) binding domains such as protein A, G, or L. ${ }^{20-22}$ However, given the broad affinity of these proteins for nearly all immunoglobulins, this class of molecules manifests in high surface fouling and background signal generation in complex matrices ${ }^{23}$ and has primarily been relegated to the areas of antibody purification and quality control. ${ }^{24}$

We have previously reported on the utility of supported lipid membranes for a variety of biosensing applications, ${ }^{25-28}$ including the development of a membrane cloaking method for carrying out indirect immunoassays in undiluted animal serum. ${ }^{29}$ For that experimental design, a supported lipid membrane was formed over an antibody functionalized gold surface, which was removed along with all superimposed serum contaminants using a mild surfactant once the crude sample was allowed to interact with the sensor. With all nonspecific components stripped away, the remaining signal could be attributed to the target compound, and furthermore, the antibody-antigen complex remained accessible to further signal enhancement mechanisms. Herein we build upon this strategy, endeavoring to improve the practical utility of protein A based immunosensors in complex matrices through utilization of antifouling lipid membranes (Figure 1). Surface-plasmon resonance (SPR) was chosen for characterization and optimization of this interface, ${ }^{30}$ since, as a label-free optical detection method, all species bound to the sensor surface can be detected, whether they are labeled or unlabeled, target or contaminant. ${ }^{31}$ Moreover, SPR has many demonstrated successes in the clinical realm, ${ }^{32}$ including analysis of disease biomarkers, ${ }^{33-36}$ hormones, 37,38 and therapeutic drugs. ${ }^{39,40}$ Direct adaptation of the previously used membrane cloaking method to the protein A coated sensor resulted in an interface that could not sufficiently prevent fouling, nor could it be stripped away along with nonspecifically bound components. Through an investigation of different lipid constituents, backfilling self-assembled monolayers, and rinsing strategies, we discovered that a lipid membrane consisting entirely of ethylphosphocholine $\left(\mathrm{EPC}^{+}\right)$was remarkably effective at reducing nonspecific binding from human blood serum and plasma onto the protein A coated sensor to undetectable amounts, allowing for quantitation of targeted antigens (i.e., IgG and cholera toxin) within these matrices. As this is in contrast with the convention of using zwitterionic/neutral compounds to reduce adsorption, fluorescence microscopy and photobleaching assays were conducted to better understand the interactions between these lipids and the underlying protein A coated surface. The results altogether demonstrate that, for this system, both the lipid membrane--sensor interaction strength and sterics play critical roles in reducing 
adsorption. When this $\mathrm{EPC}^{+}$strategy is appropriately employed, there is no sacrifice in sensitivity while carrying out analysis in undiluted blood serum or plasma compared to buffered samples. Given these successes as well as the universal nature of protein A, it can be envisioned that this surface could be translated to a variety of other clinical sensing applications using SPR and adjacent biosensing technologies.

\section{EXPERIMENTAL SECTION}

\section{Lipid Vesicle Preparation.}

Stocks of 1-palmitoyl-2-oleoyl-sn-glycero-3-phosphocholine (POPC; $5 \mathrm{mg} \mathrm{mL}^{-1}$ ), 1,2dioleoyl-sn-glycero-3-ethylphosphocholine (EPC ${ }^{+} ; 5 \mathrm{mg} \mathrm{mL}^{-1}$ ), and 1-palmitoyl-2-oleoylsn-glycero-3-phospho( $1^{\prime}$-rac-glycerol) $\left(\mathrm{POPG}^{-} ; 10 \mathrm{mg} \mathrm{mL}^{-1}\right)$ were obtained from Avanti Polar Lipids (Alabaster, AL, USA), diluted in chloroform to the designated concentrations, and stored at $-80{ }^{\circ} \mathrm{C}$. Appropriate amounts of these stock solutions were aliquoted into glass vials and dried under nitrogen to form thin lipid films, which were then stored in a vacuum desiccator overnight to remove any residual solvent. The dried lipids were resuspended in $1 \times$ PBS (10 mM Na $\left.2 \mathrm{HPO}_{4}, 1.8 \mathrm{mM} \mathrm{KH}_{2} \mathrm{PO}_{4}, 137 \mathrm{mM} \mathrm{NaCl}, 2.7 \mathrm{mM} \mathrm{KCL}, \mathrm{pH} 7.4\right)$ to a final concentration of $1 \mathrm{mg} \mathrm{mL}^{-1}$, followed by vigorous vortexing and bath sonication for $30 \mathrm{~min}$. This solution was extruded through a polycarbonate filter (Whatman, $100 \mathrm{~nm}$ ) to produce small, unilamellar vesicles of uniform size. All lipid vesicle suspensions were stored at $4{ }^{\circ} \mathrm{C}$ and used within 1 week of preparation. The final concentration of $1 \mathrm{mg} \mathrm{mL}^{-1}$ is above the critical micelle concentration $(\mathrm{cmc})$ of the lipids and is high enough to form vesicles.

\section{Gold Sensor Fabrication and Functionalization.}

BK-7 glass microscope slides (Corning, Painted Post, NY, USA) were cleaned with a boiling piranha solution $\left(3: 1 \mathrm{H}_{2} \mathrm{SO}_{4}\right.$ and $\left.30 \% \mathrm{H}_{2} \mathrm{O}_{2}\right)$ for $2 \mathrm{~h}$ and then subsequently rinsed with water and absolute ethanol before drying under compressed air. A $2 \mathrm{~nm}$ layer of chromium $\left(0.5 \AA^{-1}\right)$ followed by a $50 \mathrm{~nm}$ layer of gold $\left(1.0 \AA \mathrm{A} \mathrm{s}^{-1}\right)$ was deposited onto the glass slides using electron-beam evaporation (Temescal, Berkeley, CA, USA) at $5 \times 10^{-6}$ Torr in a Class 1000 cleanroom facility (UCR Center for Nanoscale Science \& Engineering). These gold sensor chips were rinsed with ethanol and dried under compressed air before being coated with $10 \mu \mathrm{gL}^{-1}$ thiolated protein A (Protein Mods, Madison, WI, USA) in $1 \times$ PBS for $2 \mathrm{~h}$ at room temperature (ca. $23{ }^{\circ} \mathrm{C}$ ), followed by a $1 \mathrm{mM}$ solution of 3-mercapto-1-propanol (MPO; Millipore-Sigma, St. Louis, MO, USA) in $1 \times$ PBS for $1 \mathrm{~h}$ at room temperature. The sensor chips were rinsed with nanopure water ( $\geq 18 \mathrm{M} \Omega \cdot \mathrm{cm}$, Barnstead E-Pure) and dried under a nitrogen stream after each step before final storage at $4{ }^{\circ} \mathrm{C}$. Nanoglassified gold sensor chips were prepared by depositing a thin layer of silica (ca. $2-4 \mathrm{~nm}$ ) via plasmaenhanced chemical vapor deposition using a Unaxis Plasmatherm 790 (Santa Clara, CA, USA) directly after electron-beam evaporation of gold, and these chips were not subject to any further functionalization. ${ }^{27}$

\section{SPR Analysis of Lipid Deposition and Fouling.}

Surface-plasmon resonance spectroscopy was conducted at room temperature on a NanoSPR5-321 (NanoSPR, Addison, IL, USA) using 1× PBS as the running buffer set to a flow rate of $5 \mathrm{~mL} \mathrm{~h}^{-1}$ (ca. $83 \mu \mathrm{L} \mathrm{min}{ }^{-1}$ ) unless otherwise noted. Lipid deposition was 
carried out by injection of $1 \mathrm{mg} \mathrm{mL}^{-1}$ lipid vesicles into the instrument, and the minimum angle was tracked over $1 \mathrm{~h}$ under zero flow conditions. After a $10 \mathrm{~min}$ rinse with $1 \times$ PBS, undiluted human serum (male from AB plasma, Millipore-Sigma) or plasma (pooled, Millipore-Sigma) was injected and allowed to interact with the surface under zero flow for $30 \mathrm{~min}$, before a final $15 \mathrm{~min}$ rinse with PBS.

For analysis of mouse immunoglobulin (IgG) and cholera toxin (CT) within spiked human serum and plasma, $100 \mu \mathrm{g} \mathrm{mL}^{-1}$ capture antibody (rabbit antimouse $\mathrm{IgG}$ or rabbit anti-CT, Millipore-Sigma) was incubated for $1 \mathrm{~h}$. This was followed by lipid vesicle deposition as described above, and the surface was subsequently interacted with human serum or plasma spiked with the target antigen, mouse IgG, or CT. All steps were separated by a $10 \mathrm{~min}$ PBS rinse with the exception of the postsample rinse, which was extended to $30 \mathrm{~min}$. Detection antibodies were introduced at a concentration of $10 \mu \mathrm{M}$ for $1 \mathrm{~h}$. For the nanoparticleenhanced detection, the same protocol was followed, with the addition of $100 \mu \mathrm{g} \mathrm{mL}$ streptavidin, followed by $1 \mathrm{nM} 30 \mathrm{~nm}$ biotinylated gold nanoparticles (bT $\left.\mathbf{2 0}_{\mathbf{2}} / \mathrm{AuNPs}\right){ }^{41}$

\section{Fluorescence Microscopy and Fluorescence Recovery after Photobleaching (FRAP).}

Fluorescence microscopy images were generated on an inverted Leica TCS SP5 II (Leica Microsystems, Buffalo Point, IL, USA) using the $488 \mathrm{~nm}$ argon laser line in conjunction with a $40 \times$ objective (N.A. 1.1). Photobleaching for $500 \mathrm{~ms}$ and monitoring of fluorescence recovery within defined regions of interest were performed using the LAS AF software package (Leica). Mobile fractions ( $B$ ) and diffusion coefficients $(D)$ were determined using the methods of Axelrod et al. and Soumpasis as previously reported. ${ }^{25,42,43}$

\section{RESULTS AND DISCUSSION}

\section{Formation of an Antifouling Lipid Membrane over Protein A.}

The use of protein A in immunoassay design carries the distinct advantage of being able to provide a site for optimal orientation-controlled attachment of antibodies, with the $\mathrm{Fc}$ (fragment crystallizable) region bound by protein A and directed toward the sensor surface, and the Fab (fragment antigen-binding) region extending into the sample matrix. ${ }^{20}$ Leveraging this capability for the analysis of crude samples would present a powerful tool, provided that levels of nonspecific binding are controlled. We previously developed a lipid membrane interface for antibody based detection in undiluted animal serum, which was formed over a gold surface functionalized with a mixed self-assembled monolayer (SAM) of cysteamine and 3-mercapto-1-propanol (MPO). ${ }^{29}$ Building upon this design, initial studies retained use of MPO as a spacer molecule while the cysteamine constituent was substituted with protein A. Protein A was first deposited onto the gold surface at a concentration of 10 $\mu \mathrm{g} \mathrm{mL}{ }^{-1}$ for $2 \mathrm{~h}$, and the interstitial area was backfilled with MPO. Introduction of undiluted human serum to this interface resulted in massive angular resonance shifts $\left(\Delta \theta=0.73^{\circ}\right)$, indicative of high levels of nonspecific binding that could not be rinsed away by buffer or surfactant (Figure 2A), thereby necessitating the use of a blocking agent or barrier. A membrane of zwitterionic phosphocholine (POPC) was naturally favored for this task due to the molecule's well-characterized antifouling properties and demonstrated increases in bioanalytical sensor performance. ${ }^{15,44}$ However, when a suspension of POPC vesicles was 
introduced to the protein $\mathrm{A} / \mathrm{MPO}$ surface, followed by serum, nonspecific binding remained unaffected compared to the surface without lipids (Figure 2B). Because the angular resonance shift from lipid introduction appeared low $\left(\Delta \theta<0.1^{\circ}\right)$ compared to previous SPR investigations of supported lipid bilayer formation $\left(\Delta \theta>0.45^{\circ}\right.$ over silica/silicate nanofilms on gold), ${ }^{25,27,41}$ a low surface coverage of POPC was suspected to be the issue here, thus requiring confirmatory studies using a complementary analytical technique.

Confocal fluorescence microscopy was employed to investigate the spatial distribution of fluorophore-tagged phospholipids over the protein A/MPO interface. A surrogate material was used in place of the gold SPR substrates, which consisted of a glass coverslip functionalized with a SAM of silane-PEG-maleimide (see the Supporting Information for fabrication details). This surface provided an even monolayer of thiol-reactive sites, analogous to gold, though circumvented the issue of fluorescent quenching by nonradiative energy transfer to the gold surface. Once protein A, MPO, and a suspension of POPC vesicles containing a fluorophore-labeled constituent ( $2 \mathrm{wt} \%$ NBD-PC) were applied as described above, the surface was kept submerged in an aqueous environment and imaged. From the image in Figure 2B, the distribution of fluorescence appears patchy and uneven, indicating that POPC vesicle adsorption was inefficient, thereby leaving large areas of the protein $\mathrm{A} / \mathrm{MPO}$ surface exposed to incoming contaminants from the sample matrix. Utilization of these lipid membranes to combat nonspecific binding would require a more targeted approach in which lipid interactions with the underlying surface were discretely considered.

Although the formation of supported lipid bilayers via the fusion of small unilamellar vesicles (SUVs) is conventionally carried out over smooth, rigid, and hydrophilic surfaces, $25,27,45$ lipid membranes have also been formed over a variety of SAMs in which interactions with lipid headgroups were electrostatically favored. ${ }^{46,47}$ Given that the theoretical isoelectric point (pI) of protein A is ca. $5.4,{ }^{48}$ the protein A/MPO sensor surface is expected to carry a net negative charge within our running buffer at $\mathrm{pH}$ 7.4. Therefore, it was hypothesized that lipid vesicles exhibiting a net positive charge would be required for greater surface interaction strength toward forming a contiguous barrier. Indeed, when a new vesicle suspension consisting solely of a positively charged lipid, ethylphosphocholine (EPC ${ }^{+}$), was introduced to the protein A/MPO surface, resonance angular shifts increased by ca. $0.7^{\circ}$ compared to POPC, suggesting that the surface was more completely coated with lipids (Figure 2C). This was confirmed by fluorescence microscopy of labeled ( 2 wt $\%$ NBD-PC) $\mathrm{EPC}^{+}$vesicles deposited on protein A/MPO, revealing a more complete and even distribution of fluorescence (Figure 2C). Interestingly, upon introduction of human serum to the $\mathrm{EPC}^{+}$laden surface, a lower angular shift was observed $\left(\Delta \theta=0.5^{\circ}\right)$ compared to the untreated and POPC modified surfaces $\left(\Delta \theta=0.73^{\circ}\right)$. This signal remarkably returned to the baseline $\mathrm{EPC}^{+}$value postincubation $(1 \mathrm{~h})$ and a buffer rinse $(10 \mathrm{~min})$, suggesting that all serum contaminants can easily be removed without also having to strip away the membrane. The $\mathrm{EPC}^{+}$lipids remain stably bound to the surface after this time, exhibiting no decrease in angular shift, which would be indicative of detachment or deterioration of the interface, even after an extended $(2 \mathrm{~h})$ rinse under a constant flow of buffer (Supporting Information Figure $\mathrm{S} 1)$. The use of a mixed lipid vesicle suspension consisting of 50\% $\mathrm{POPC}$ and $\mathrm{EPC}^{+}$was also investigated in an attempt to see if the overall charge could be reduced (Figure S2), 
though while the results were better than POPC alone, a fair amount of serum material remained on the surface after the buffer wash $\left(\Delta \theta=0.34^{\circ}\right)$. In an effort to more completely validate the idea that charge-matching between these lipids and the underlying surface is necessary for complete coverage, negatively charged $\mathrm{POPG}^{-}$vesicles were investigated for their antifouling properties. However, much like the POPC vesicles, a low $\left(\Delta \theta<0.1^{\circ}\right)$ angular resonance shift was observed upon introduction of lipids to the surface, as well as a high $\left(\Delta \theta=0.59^{\circ}\right)$ level of nonspecific binding from serum that could not be rinsed away under flow of buffer (Figure S3). Therefore, tailoring the charge of these lipid vesicles to their underlying surface chemistry appears critical for enabling successful formation of a supported lipid membrane over protein A, in turn rendering it resistant to biofouling from human serum.

\section{Extension to Undiluted Human Plasma.}

Blood plasma is generally prepared by introducing anticoagulants to whole blood and centrifuging to collect the supernatant, requiring less technical expertise and considered less time-consuming to separate than serum. Although it is a more complex medium, containing fibrinogen and other clotting factors that are absent from serum, a high interest in plasma profiling exists due to its comparatively facile preparation and higher reproducibility in the characterization of select metabolites and proteins. ${ }^{49-51}$ Given that the $\mathrm{EPC}^{+}$lipid membrane over protein A/MPO demonstrated high antifouling activity against human serum, translatability to other crude fluids such as plasma presented a tantalizing possibility and was therefore investigated (Figure 3). High levels of nonspecific interactions over the protein A/MPO surface were once again observed $\left(\Delta \theta=0.72^{\circ}\right)$ when undiluted human plasma was incubated over the surface in the absence of any lipids (Figure 3A). This observation reiterates that although protein $\mathrm{A}$ is ideal for antibody orientation and ease of attachment, it does represent one of the more universally difficult surface chemistries to work with for clinical sample analysis. However, once $\mathrm{EPC}^{+}$lipids have been deposited over this surface, nonspecifically bound components from plasma can be completely removed under a buffer flow, in a manner identical to that of the serum samples (Figure 3B). Therefore, either matrix should be compatible for immunosensing over this protein A/MPO surface chemistry in conjunction with the $\mathrm{EPC}^{+}$lipid barrier.

\section{Performance-Affecting Considerations.}

With successful $\mathrm{EPC}^{+}$deposition and antifouling activity, we sought to define other parameters that could affect the performance of this interface; that is, whether certain experimental variables are robust enough to be altered without any notable decrease in performance, or whether a delicate balance exists between these variables. Injection of $\mathrm{POPC}$ or $\mathrm{EPC}^{+}$vesicle suspensions over a planar, silica surface resulted in altered deposition and antifouling effectiveness compared to the protein A/MPO surface, which we suspected to be attributed to differences in hydrophilicity and adsorbed surface features (e.g., from protein A and SAMs) (Figure S4). The effect of increasing the density of protein A deposited on the gold surface was investigated, which consisted of raising the incubation concentration from 10 to $100 \mu \mathrm{g} \mathrm{mL}^{-1}$. MPO was retained for backfilling of interstitial space, and $\mathrm{EPC}^{+}$injection and serum effects were analyzed by SPR. Effects of raising this concentration were deleterious, however, with a lower resonance angle shift $\left(\Delta \theta=0.6^{\circ}\right)$ for 
the lipids and increased nonspecific binding $\left(\Delta \theta=0.4^{\circ}\right)$ from undiluted serum (Figure S5). Conversely, the effects of holding $10 \mu \mathrm{g} \mathrm{mL}^{-1}$ protein A constant while replacing MPO with other selected SAMs was tested. 3-Mercaptopropionic acid (MPA) was selected for its similar length to MPO, though functionalized with a different end terminal (i.e., carboxylic acid) and charge, while 11-mercapto-1-undecanol (MUO) was selected for its identical end terminal functionalization (i.e., hydroxyl) and longer length. A protein A surface without any backfilling SAM was also included in this investigation. While the $\mathrm{EPC}^{+}$lipids were successfully deposited on all surfaces at a level similar to that of protein A/MPO ( $\Delta \theta \sim$ $0.8^{\circ}$ ), nonspecific interactions with serum were notably different (Figure S6). Both the protein A surface with no SAM and MPA-backfilled surfaces exhibited a higher level of nonspecific binding than protein A/MPO $\left(\Delta \theta=0.1^{\circ}\right)$, though this was still minimal in comparison to a surface in which serum was introduced without $\operatorname{EPC}^{+}\left(\Delta \theta=0.73^{\circ}\right.$, Figure 2A). MUO faired the least successful of the SAMs studied, with an angular shift of ca. $0.25^{\circ}$ after serum was introduced and rinsed with buffer. From these data, the packing density of protein A on the gold surface at $10 \mu \mathrm{g} \mathrm{mL}-1$ provides sufficient interstitial space for backfilling by an appropriate SAM. While MPO has proven to be the most efficient backfilling agent chosen, it can be inferred that the length of this SAM is the most critical parameter to balance against protein A surface chemistry, with the end terminal functionality playing a comparatively more minor role.

\section{Lipid-Surface Interactions and Lateral Mobility.}

In light of this specific amalgam (i.e., protein $\mathrm{A}, \mathrm{MPO}$, and $100 \% \mathrm{EPC}^{+}$) giving rise to such high antifouling efficacy, in contrast with the convention of using zwitterionic/neutral SAMs and brush networks for this purpose, ${ }^{14,52}$ we sought a better understanding of how EPC ${ }^{+}$ assembles and interacts with the underlying protein A/MPO surface. Fluorescence recovery after photobleaching (FRAP) was employed to shed light on these interactions and glean information on the architecture of surface-adsorbed $\mathrm{EPC}^{+}$structures. FRAP has been used to measure the lateral mobility of fluorescent molecules within liquids, ${ }^{53}$ hydrogels,,${ }^{53,54}$ and lipid bilayers. ${ }^{25,27}$ In principle, mobility kinetics may be assessed by bleaching a selected two-dimensional area under high laser intensity and monitoring the recovery of fluorescence within the bleached region as nonbleached molecules laterally diffuse and redistribute.

Applied toward the study of lipid membranes supported by solid surfaces, only lipids within a contiguous lipid bilayer formed by fusion of adsorbed vesicles will exhibit measurable diffusivities (i.e., measure of the speed at which lipids are diffusing). If the diffusivity is low or the lipids are completely immobile, strong interactions with the surface or lack of vesicle fusion, both of which prevent long-range mobility, could be inferred. ${ }^{25,45}$ When EPC ${ }^{+}$ vesicles are applied to a glass support, a supported lipid bilayer is formed similar to POPC membranes on glass (Figure 4A). ${ }^{25,27}$ The lipids embedded within the $\mathrm{EPC}^{+}$membrane are fluid and mobile, exhibiting a diffusivity $(D)$ of $1.87 \pm 0.12 \mu \mathrm{m}^{2} \mathrm{~s}^{-1}$ and a mobile fraction $(\beta)$ of $97 \%\left(R^{2}=0.97\right)$, with $\beta$ serving as an indicator of the percentage of lipids that are freely diffusing (Figure 4B). In contrast, $\mathrm{EPC}^{+}$vesicles deposited over protein A/MPO behave far differently, exhibiting no redistribution of fluorescence within the region of interest after photobleaching (Figure 4A). Attempting to extract diffusivity and mobile fractions from these data results in near negligible values that do not fit the model for lateral lipid diffusion $\left(R^{2}=0.23\right)$, suggesting that these lipids, while appearing continuous and 
uniform, are tightly bound via strong electrostatic interactions to the underlying protein $\mathrm{A} / \mathrm{MPO}$ surface. For reference, $50 \% \mathrm{POPC} / \mathrm{EPC}^{+}$vesicles exhibited a similar pattern in mobility, albeit with the FRAP results suggesting that the membrane is not as tightly bound to protein A/MPO with $D=0.42 \pm 0.35 \mu \mathrm{m}^{2} \mathrm{~s}^{-1}$ and $\beta=44 \%\left(R^{2}=0.99\right)$ (Figure S7). The FRAP results confirm that $\mathrm{EPC}^{+}$vesicles are tightly bound to the protein A/MPO surface after their introduction and that the diffusional characteristics of embedded lipids are far different than conventional phosphocholine based supported lipid bilayers on glass. Taken together with the antifouling characteristics unique to this identified set of constituents, the strong adsorption and self-assembled architecture of $\mathrm{EPC}^{+}$on protein $\mathrm{A} / \mathrm{MPO}$ appear to play critical roles for reduction of nonspecific binding. ${ }^{55}$

\section{Targeted Detection of Antibodies and Bacterial Toxins in Crude Biofluids.}

In order to confirm that this lipid membrane could be used in an immunosensing application and retain its high antifouling properties, a biosensor for $\operatorname{IgG}$ was constructed through incubation of a capture antibody, anti-IgG, over protein $\mathrm{A} / \mathrm{MPO}$ prior to the introduction of IgG spiked serum. For this proof of concept experiment the selected capture antibody was raised against mouse, from which the target antigen was also procured, so that human antibodies present in serum or plasma would not be recognized. The binding of this capture antibody $\left(100 \mu \mathrm{g} \mathrm{m}^{-1}\right)$ to protein A was confirmed by $\operatorname{SPR}\left(\Delta \theta=0.17^{\circ}\right.$, Figure $\left.5 \mathrm{~A}\right)$, as was the deposition of $\mathrm{EPC}^{+}\left(\Delta \theta=0.55^{\circ}\right)$. The reduction of angular shift during $\mathrm{EPC}^{+}$ introduction compared to when no capture antibody is present $\left(\Delta \theta=0.8^{\circ}\right.$, Figure $\left.2 \mathrm{C}\right)$ is attributed to IgG being bound by protein $\mathrm{A}$ on the surface, thus reducing available deposition area. Blood plasma (Figure 5A) or serum (Figure S8) spiked with $\operatorname{IgG}\left(10 \mu \mathrm{g} \mathrm{mL}^{-1}\right)$ was then incubated over the surface for $1 \mathrm{~h}$. While the majority of nonspecific components from plasma or serum can still be removed using a buffer rinse, no significant change in angular shift is observed between the samples with and without IgG. This is common in the detection of lowly abundant analytes in complex matrices, and the issue was overcome by simple addition of a detection antibody (i.e., anti-IgG) for indirect measurement. ${ }^{32,56}$ Once introduced, angular shifts from the detection antibody were only observed for samples spiked with $\operatorname{IgG}\left(\Delta \theta=0.25^{\circ}\right)$, confirming specificity. This detection signal exhibits very little variation whether the matrix is plasma, serum, or PBS, and moreover, the $\mathrm{EPC}^{+}$lipids appear to provide no deleterious effects on sensitivity, with a relative standard deviation (RSD) of only $9.7 \%$ between all experimental conditions (Figure S9). The use of protein A in place of a traditional coupling scheme (i.e., EDC/NHS coupling over a mercaptoundecanoic acid surface) also proves advantageous, with higher detection antibody signal observed when protein A is used (Figure S10), which is likely due to optimal capture antibody orientation.

To demonstrate the versatility of this approach beyond $\operatorname{IgG}$ detection, specific recognition of cholera toxin in undiluted human serum was also performed. Secreted by Vibrio cholerae, cholera toxin (CT) has brought major disease burdens to developing areas worldwide. Though it targets the small intestine and is primarily diagnosed from stool, transport to the bloodstream though the jejunum has been documented, ${ }^{57}$ which may provide an additional vantage point in the characterization of disease progression. ${ }^{58}$ Once anti-CT $\left(100 \mu \mathrm{g} \mathrm{mL}{ }^{-1}\right)$ was immobilized on protein $\mathrm{A} / \mathrm{MPO}$, the antifouling capabilities of the $\mathrm{EPC}^{+}$lipids were 
still observed, as demonstrated by the angular shift returning to baseline after the buffer rinse (Figure 5B). Similar to IgG, no direct measurement of CT $\left(10 \mu \mathrm{gL}^{-1}\right)$ was noted, though specific binding of CT was readily confirmed using a detection antibody (i.e., anti-CT) enhancement step, yielding an angular shift of $0.05^{\circ}$. While this signal is lower than that for indirect $\operatorname{IgG}$ measurement, it is anticipated that a stringent screening for matching capture and detection antibody pairs will improve results. ${ }^{59}$ Nonetheless, this angular shift was proven to be concentration dependent, demonstrating the promise of this platform for targeted quantitation of biomarkers in crude samples (Figure S11) and confirming the results obtained for IgG measurement.

While the above sensitivities should prove sufficient for many applications, there are a plethora of biomarkers that require more sensitive detection strategies for accurate clinical diagnoses and decisions to be made. Ultrasensitive SPR analysis can be achieved through electromagnetic coupling of metallic nanoparticles with the sensor chip, substantially lowering limits of detection. ${ }^{32,37,41} \mathrm{We}$ therefore included additional enhancement steps to each of our model assays with the goal of targeted gold nanoparticle binding. Detection antibodies were conjugated with biotin and introduced at a concentration of $1 \mu \mathrm{M}$. Using a streptavidin bridge ( $\left.100 \mu \mathrm{g} \mathrm{mL}^{-1}\right)$, the interaction of biotin-labeled gold nanoparticles (bT $\mathbf{2 0}_{\mathbf{2 0}} / \mathrm{AuNPs}$ ) was quantified and used to investigate the interaction specificity in the presence of the $\mathrm{EPC}^{+}$barrier (Figure 5C). Although we do see some background binding from streptavidin, and hence, the $\mathbf{b} \mathbf{T}_{\mathbf{2 0}} / \mathrm{AuNPs}$, we can still easily discriminate between when $\operatorname{IgG}\left(10 \mu \mathrm{g} \mathrm{mL}^{-1}\right)$ is present in serum $\left(\Delta \theta=0.30^{\circ}\right)$ and when it is not $\left(\Delta \theta=0.10^{\circ}\right)$. Similar results were obtained for nanoparticle-enhanced CT $\left(0.05 \mu \mathrm{g} \mathrm{mL}{ }^{-1}\right)$ detection (Figure S12), where background signal $\left(\Delta \theta=0.08^{\circ}\right)$ was lower than target-specific signal $\left(\Delta \theta=0.21^{\circ}\right)$. Given that these $\mathbf{b T}_{\mathbf{2 0}} / \mathrm{AuNPs}$ have been designed to carry a high density of negative charge through DNA spacers for maximum colloidal stability, ${ }^{41}$ it is impressive that specific recognition is retained over $\mathrm{EPC}^{+}$carrying a net positive charge, from which an excessively high background would be expected. The limit of detection, measured with cholera toxin, could reach $0.05 \mu \mathrm{g} / \mathrm{mL}$ with gold nanoparticle enhancement (Figure S12). The limit of detection is also reported in terms of the number of molecules, which is summarized in Table S1. While the antifouling membrane formed over protein A/MPO is resistant to fouling from common blood derivatives, it could also be used in conjunction with other materials, organic or inorganic, for sensitive and specific recognition of clinically relevant targets.

\section{CONCLUSIONS}

We have reported the use of charge-matched lipid membranes as an antifouling surface capable of carrying out analysis in undiluted human serum and plasma. By tailoring the charge of the lipid vesicles used, as well as selection of an appropriate backfilling SAM, the membrane successfully formed over a protein A surface, additionally allowing for orientation-controlled immunosensing. We have shown that the addition of this membrane caused no reduction in SPR signal for antibody and bacterial toxin detection and that analysis in complex matrices could be carried out with results similar to those seen for buffered samples. 
With these successes, a number of opportunities are presented for future exploration. While interactions between $\mathrm{EPC}^{+}$and protein $\mathrm{A} / \mathrm{MPO}$ were characterized here, revealing them to be exceptionally strong and starkly different from those involving zwitterionic POPC, further biophysical studies (e.g., DLS/ELS, LDI-MS) are warranted to determine how specific biofluid contaminants interact with each of these lipid species, rendering them different from each other, and even commonly used poly(ethylene glycol) monolayers. These insights will assist in the tailored design and optimization of this and other antifouling surface chemistries that incorporate phospholipid constituents. Multiplexing, while not explored herein, will also be desired for diagnosis of multiple diseases and/or patients at once, or for cross-validation of biomarkers. Lipid membranes are notoriously difficult to work with for this purpose, though addition of trehalose during lipid deposition has been proven to preserve the structural integrity of lipid vesicles adsorbed to surfaces during drying/desiccation and could be adopted for protein A/MPO. ${ }^{27}$ Such a design would allow for biosensor construction with all necessary constituents in advance, preserving components in spatially defined locations until the assay(s) is ready to be run, thereby streamlining analysis.

Moving forward and given the universal nature of protein A, this surface chemistry could potentially be used in a range of surface based biosensing platforms. Current techniques aside from SPR, including ELISA, fluorescent microarrays, and electrochemical based methods of analysis, which also suffer from nonideal antibody orientation and ineffective surface blocking, could benefit from this novel surface chemistry, allowing for the sensing of clinically relevant targets within a range of complex biological matrices.

\section{Supplementary Material}

Refer to Web version on PubMed Central for supplementary material.

\section{ACKNOWLEDGMENTS}

We gratefully acknowledge financial supports from the National Science Foundation (Grant CHE-1413449) and National Institutes of Health (Grant R21AI140461), as well as Luna Technologies and the United States Army (USAMRAA). S.S.H. was supported by a University of California, Riverside (UCR) Dissertation Year Program (DYP) fellowship and an NIEHS T32 training grant (T32 ES018827). Confocal microscopy images were generated at the Microscopy Core within the Institute for Integrative Genome Biology at the University of California, Riverside.

\section{REFERENCES}

(1). McKeating KS; Aube A; Masson J-F. Biosensors and nanobiosensors for therapeutic drug and response monitoring. Analyst 2016, 141 (2), 429-449. [PubMed: 26631282]

(2). Blaszykowski C; Sheikh S; Thompson M. A survey of state-of-the-art surface chemistries to minimize fouling from human and animal biofluids. Biomater. Sci 2015, 3 (10), 1335-1370. [PubMed: 26215763]

(3). Liu B; Liu X; Shi S; Huang R; Su R; Qi W; He Z. Design and mechanisms of antifouling materials for surface plasmon resonance sensors. Acta Biomater 2016, 40, 100-118. [PubMed: 26921775]

(4). Bakker E. So, You Have a Great New Sensor. How Will You Validate It? ACS Sens 2018, 3 (8), 1431. [PubMed: 30139264] 
(5). Wade JH; Alsop AT; Vertin NR; Yang HW; Johnson MD; Bailey RC. Rapid, Multiplexed Phosphoprotein Profiling Using Silicon Photonic Sensor Arrays. ACS Cent. Sci 2015, 1 (7), 374382. [PubMed: 26539563]

(6). Washburn AL; Shia WW; Lenkeit KA; Lee SH; Bailey RC. Multiplexed cancer biomarker detection using chip-integrated silicon photonic sensor arrays. Analyst 2016, 141 (18), 53585365. [PubMed: 27400767]

(7). Pelaez EC; Estevez M-C; Portela A; Salvador J-P; Marco M-P; Lechuga LM. Nanoplasmonic biosensor device for the monitoring of acenocoumarol therapeutic drug in plasma. Biosens. Bioelectron 2018, 119, 149-155. [PubMed: 30125875]

(8). Ramirez-Priego P; Martens D; Elamin AA; Soetaert P; Van Roy W; Vos R; Anton B; Bockstaele R; Becker H; Singh M; Bienstman P; Lechuga LM. Label-Free and Real-Time Detection of Tuberculosis in Human Urine Samples Using a Nanophotonic Point-of-Care Platform. ACS Sens 2018, 3, 2079-2086. [PubMed: 30269480]

(9). Ng AHC; Fobel R; Fobel C; Lamanna J; Rackus DG; Summers A; Dixon C; Dryden MDM; Lam C; Ho M; Mufti NS; Lee V; Asri MAM; Sykes EA; Chamberlain MD; Joseph R; Ope M; Scobie HM; Knipes A; Rota PA; Marano N; Chege PM; Njuguna M; Nzunza R; Kisangau N; Kiogora J; Karuingi M; Burton JW; Borus P; Lam E; Wheeler AR. A digital microfluidic system for serological immunoassays in remote settings. Sci. Transl. Med 2018, 10 (438), eaar6076. [PubMed: 29695457]

(10). Peungthum P; Sudprasert K; Amarit R; Somboonkaew A; Sutapun B; Vongsakulyanon A; Seedacoon W; Kitpoka P; Kunakorn M; Srikhirin T. Surface plasmon resonance imaging for $\mathrm{ABH}$ antigen detection on red blood cells and in saliva: secretor status-related ABO subgroup identification. Analyst 2017, 142 (9), 1471-1481. [PubMed: 28345691]

(11). Blaszykowski C; Sheikh S; Thompson M. Surface chemistry to minimize fouling from bloodbased fluids. Chem. Soc. Rev 2012, 41 (17), 5599-5612. [PubMed: 22772072]

(12). Aube A; Breault-Turcot J; Chaurand P; Pelletier JN; Masson JF. Non-specific Adsorption of Crude Cell Lysate on Surface Plasmon Resonance Sensors. Langmuir 2013, 29 (32), 1014110148. [PubMed: 23845017]

(13). Aube A; Campbell S; Schmitzer AR; Claing A; Masson J-F. Ultra-low fouling methylimidazolium modified surfaces for the detection of HER2 in breast cancer cell lysates. Analyst 2017, 142 (13), 2343-2353. [PubMed: 28560368]

(14). Lísalová H; Brynda E; Houska M; Víšová I; Mrkvová K; Song XC; Gedeonová E; Surman F; Riedel T; Pop-Georgievski O; Homola J. Ultralow-Fouling Behavior of Biorecognition Coatings Based on Carboxy-Functional Brushes of Zwitterionic Homo- and Copolymers in Blood Plasma: Functionalization Matters. Anal. Chem 2017, 89 (6), 3524-3531. [PubMed: 28233990]

(15). Li H; Dauphin-Ducharme P; Arroyo-Curras N; Tran CH; Vieira PA; Li S; Shin C; Somerson J; Kippin TE; Plaxco KW. A Biomimetic Phosphatidylcholine-Terminated Monolayer Greatly Improves the In Vivo Performance of Electrochemical Aptamer-Based Sensors. Angew. Chem., Int. Ed 2017, 56 (26), 7492-7495.

(16). Goda T; Tabata M; Sanjoh M; Uchimura M; Iwasaki Y; Miyahara Y. Thiolated 2methacryloyloxyethyl phosphorylcholine for an antifouling biosensor platform. Chem. Commun 2013, 49 (77), 8683-8685.

(17). Akkahat P; Kiatkamjornwong S; Yusa S.-i.; Hoven VP; Iwasaki Y. Development of a Novel Antifouling Platform for Biosensing Probe Immobilization from Methacryloyloxyethyl Phosphorylcholine-Containing Copolymer Brushes. Langmuir 2012, 28 (13), 5872-5881. [PubMed: 22364521]

(18). Gong YK; Liu LP; Messersmith PB. Doubly biomimetic catecholic phosphorylcholine copolymer: a platform strategy for fabricating antifouling surfaces. Macromol. Biosci 2012, 12 (7), 979-985. [PubMed: 22610777]

(19). Lim CY; Owens NA; Wampler RD; Ying Y; Granger JH; Porter MD; Takahashi M; Shimazu K. Succinimidyl Ester Surface Chemistry: Implications of the Competition between Aminolysis and Hydrolysis on Covalent Protein Immobilization. Langmuir 2014, 30 (43), 12868-12878. [PubMed: 25317495] 
(20). Valsecchi C; Jones T; Wang C; Lochbihler H; Menezes JW; Brolo AG. Low-Cost Leukemic Serum Marker Screening Using Large Area Nanohole Arrays on Plastic Substrates. ACS Sens 2016, 1 (9), 1103-1109.

(21). Iijima M; Kuroda S. i. Scaffolds for oriented and close-packed immobilization of immunoglobulins. Biosens. Bioelectron 2017, 89, 810-821. [PubMed: 27818052]

(22). Taheri RA; Rezayan AH; Rahimi F; Mohammadnejad J; Kamali M. Development of an immunosensor using oriented immobilized anti-OmpW for sensitive detection of Vibrio cholerae by surface plasmon resonance. Biosens. Bioelectron 2016, 86, 484-488. [PubMed: 27442077]

(23). Zeidan E; Li SQ; Zhou ZG; Miller J; Sandros MG. Single-Multiplex Detection of Organ Injury Biomarkers using SPRi based Nano-Immunosensor. Sci. Rep 2016, 6, 36348. [PubMed: 27796342]

(24). Hou KC; Zaniewski R; Roy S. Protein A immobilized affinity cartridge for immunoglobulin purification. Biotechnol. Appl. Biochem 1991, 13 (2), 257-268. [PubMed: 2043281]

(25). Hinman SS; Ruiz CJ; Cao Y; Ma MC; Tang JJ; Laurini E; Posocco P; Giorgio S; Pricl S; Peng L; Cheng Q. Mix and Match: Coassembly of Amphiphilic Dendrimers and Phospholipids Creates Robust, Modular, and Controllable Interfaces. ACS Appl. Mater. Interfaces 2017, 9 (1), 10291035. [PubMed: 27957833]

(26). Perez L; Mettry M; Hinman SS; Byers SR; McKeating KS; Caulkins BG; Cheng Q; Hooley RJ. Selective protein recognition in supported lipid bilayer arrays by tailored, dual-mode deep cavitand hosts. Soft Matter 2017, 13, 3966-3974. [PubMed: 28512660]

(27). Hinman SS; Ruiz CJ; Drakakaki G; Wilkop TE; Cheng Q. On-Demand Formation of Supported Lipid Membrane Arrays by Trehalose-Assisted Vesicle Delivery for SPR Imaging. ACS Appl. Mater. Interfaces 2015, 7 (31), 17122-17130. [PubMed: 26193345]

(28). Liu Y; Cheng Q. Detection of Membrane-Binding Proteins by Surface Plasmon Resonance with an All-Aqueous Amplification Scheme. Anal. Chem 2012, 84 (7), 3179-3186. [PubMed: 22439623]

(29). Phillips KS; Han JH; Cheng Q. Development of a "membrane cloaking" method for amperometric enzyme immunoassay and surface plasmon resonance analysis of proteins in serum samples. Anal. Chem 2007, 79 (3), 899-907. [PubMed: 17263314]

(30). Lee TH; Hirst DJ; Kulkarni K; Del Borgo MP; Aguilar MI. Exploring Molecular-Biomembrane Interactions with Surface Plasmon Resonance and Dual Polarization Interferometry Technology: Expanding the Spotlight onto Biomembrane Structure. Chem. Rev 2018, 118 (11), 5392-5487. [PubMed: 29793341]

(31). Hinman SS; McKeating KS; Cheng Q. Surface Plasmon Resonance: Material and Interface Design for Universal Accessibility. Anal. Chem 2018, 90 (1), 19-39. [PubMed: 29053253]

(32). Masson JF. Surface Plasmon Resonance Clinical Biosensors for Medical Diagnostics. ACS Sens 2017, 2 (1), 16-30. [PubMed: 28722437]

(33). Yang C-T; Pourhassan-Moghaddam M; Wu L; Bai P; Thierry B. Ultrasensitive Detection of Cancer Prognostic miRNA Biomarkers Based on Surface Plasmon Enhanced Light Scattering. ACS Sens 2017, 2 (5), 635-640. [PubMed: 28723162]

(34). Jayanthi VSPKSA; Das AB; Saxena U. Recent advances in biosensor development for the detection of cancer biomarkers. Biosens. Bioelectron 2017, 91, 15-23. [PubMed: 27984706]

(35). Kim S; Wark AW; Lee HJ. Femtomolar Detection of Tau Proteins in Undiluted Plasma Using Surface Plasmon Resonance. Anal. Chem 2016, 88 (15), 7793-7799. [PubMed: 27399254]

(36). Nie W; Wang Q; Zou L; Liu X; Yang X; Wang K; Zheng Y. Low-Fouling Surface Plasmon Resonance Sensor for Highly Sensitive Detection of MicroRNA in a Complex Matrix Based on the DNA Tetrahedron. Anal. Chem 2018, 90, 12584-12591. [PubMed: 30346693]

(37). Yockell-Lelievre H; Bukar N; McKeating KS; Arnaud M; Cosin P; Guo Y; Dupret-Carruel J; Mougin B; Masson JF. Plasmonic sensors for the competitive detection of testosterone. Analyst 2015, 140 (15), 5105-5111. [PubMed: 26034786]

(38). Cao Y; McDermott MT. A surface plasmon resonance based inhibition immunoassay for measurement of steroid hormones. Anal. Biochem 2018, 557, 7-12. [PubMed: 29964030]

(39). Ilkhani H; Farhad S. A novel electrochemical DNA biosensor for Ebola virus detection. Anal. Biochem 2018, 557, 151-155. [PubMed: 29908157] 
(40). Lu J; Spasic D; Delport F; Van Stappen T; Detrez I; Daems D; Vermeire S; Gils A; Lammertyn J. Immunoassay for Detection of Infliximab in Whole Blood Using a Fiber-Optic Surface Plasmon Resonance Biosensor. Anal. Chem 2017, 89 (6), 3664-3671. [PubMed: 28222600]

(41). Hinman SS; McKeating KS; Cheng Q. DNA Linkers and Diluents for Ultrastable Gold Nanoparticle Bioconjugates in Multiplexed Assay Development. Anal. Chem 2017, 89 (7), 42724279. [PubMed: 28316233]

(42). Axelrod D; Koppel DE; Schlessinger J; Elson E; Webb WW. Mobility Measurement by Analysis of Fluorescence Photobleaching Recovery Kinetics. Biophys. J 1976, 16 (9), 1055-1069. [PubMed: 786399]

(43). Soumpasis DM. Theoretical-Analysis of Fluorescence Photobleaching Recovery Experiments. Biophys. J 1983, 41 (1), 95-97. [PubMed: 6824758]

(44). Phillips KS; Han JH; Martinez M; Wang ZZ; Carter D; Cheng Q. Nanoscale glassification of gold substrates for surface plasmon resonance analysis of protein toxins with supported lipid membranes. Anal. Chem 2006, 78 (2), 596-603. [PubMed: 16408945]

(45). Hinman SS; Nguyen RCT; Cheng Q. Plasmonic nanodisc arrays on calcinated titania for multimodal analysis of phosphorylated peptides. RSC Adv 2017, 7 (76), 48068-48076. [PubMed: 30701066]

(46). Wang ZZ; Wilkop T; Han JH; Dong Y; Linman MJ; Cheng Q. Development of air-stable, supported membrane arrays with photolithography for study of phosphoinositide - Protein interactions using surface plasmon resonance imaging. Anal. Chem 2008, 80 (16), 6397-6404. [PubMed: 18620431]

(47). Hinman SS; McKeating KS; Cheng Q. Plasmonic Sensing with 3D Printed Optics. Anal. Chem 2017, 89 (23), 12626-12630. [PubMed: 29156138]

(48). Kozlowski LP. IPC - Isoelectric Point Calculator. Biol. Direct 2016, 11 (1), 55. [PubMed: 27769290]

(49). Yu ZH; Kastenmuller G; He Y; Belcredi P; Moller G; Prehn C; Mendes J; Wahl S; RoemischMargl W; Ceglarek U; Polonikov A; Dahmen N; Prokisch H; Xie L; Li YX; Wichmann HE; Peters A; Kronenberg F; Suhre K; Adamski J; Illig T; Wang-Sattler R. Differences between Human Plasma and Serum Metabolite Profiles. PLoS One 2011, 6 (7), e21230-e21230. [PubMed: 21760889]

(50). Oddoze C; Lombard E; Portugal H. Stability study of 81 analytes in human whole blood, in serum and in plasma. Clin. Biochem 2012, 45 (6), 464-469. [PubMed: 22285385]

(51). Geyer PE; Kulak NA; Pichler G; Holdt LM; Teupser D; Mann M. Plasma Proteome Profiling to Assess Human Health and Disease. Cell Syst 2016, 2 (3), 185-195. [PubMed: 27135364]

(52). Zhang Z; Chao T; Chen SF; Jiang SY. Superlow fouling sulfobetaine and carboxybetaine polymers on glass slides. Langmuir 2006, 22 (24), 10072-10077. [PubMed: 17107002]

(53). Deschout H; Hagman J; Fransson S; Jonasson J; Rudemo M; Loren N; Braeckmans K. Straightforward FRAP for quantitative diffusion measurements with a laser scanning microscope. Opt. Express 2010, 18 (22), 22886-22905. [PubMed: 21164628]

(54). Ramanujan S; Pluen A; McKee TD; Brown EB; Boucher Y; Jain RK. Diffusion and convection in collagen gels: Implications for transport in the tumor interstitium. Biophys. J 2002, 83 (3), 16501660. [PubMed: 12202388]

(55). This architecture may consist of a tightly packed monolayer of adsorbed vesicles, or an immobile bilayer of EPC supported by protein A/MPO. Since the vesicle diameter (ca. $100 \mathrm{~nm}$ ) is below the diffraction limit of our microscope, neither could be confirmed by the fluorescence microscopy/FRAP studies.

(56). Aubé A; Charbonneau DM; Pelletier JN; Masson J-F. Response Monitoring of Acute Lymphoblastic Leukemia Patients Undergoing 1-Asparaginase Therapy: Successes and Challenges Associated with Clinical Sample Analysis in Plasmonic Sensing. ACS Sens 2016, 1 (11), 1358-1365.

(57). Vaughan Williams EM; Dohadwalla AN. Absorption of Cholera Toxin into Blood from a Separated Jejunal Segment. Nature 1967, 215, 552-553. [PubMed: 6057937] 
(58). Harris JB; Khan AI; LaRocque RC; Dorer DJ; Chowdhury F; Faruque AS; Sack DA; Ryan ET; Qadri F; Calderwood SB. Blood group, immunity, and risk of infection with Vibrio cholerae in an area of endemicity. Infect. Immun 2005, 73 (11), 7422-7. [PubMed: 16239542]

(59). Couture M; Ray KK; Poirier-Richard H-P; Crofton A; Masson J-F. 96-Well Plasmonic Sensing with Nanohole Arrays. ACS Sens 2016, 1 (3), 287-294. 
A

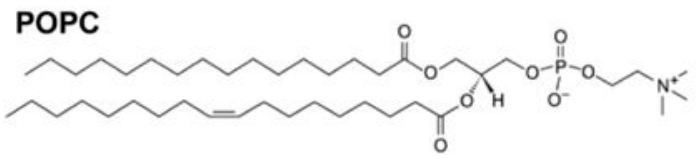

EPC
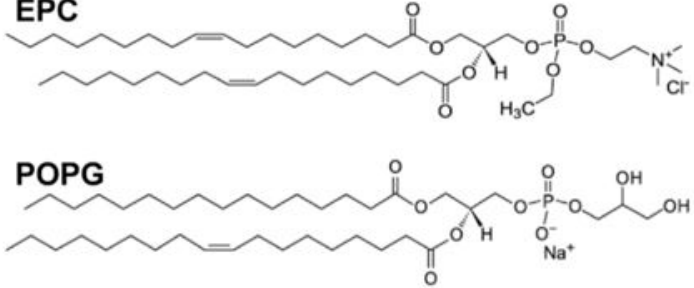

B

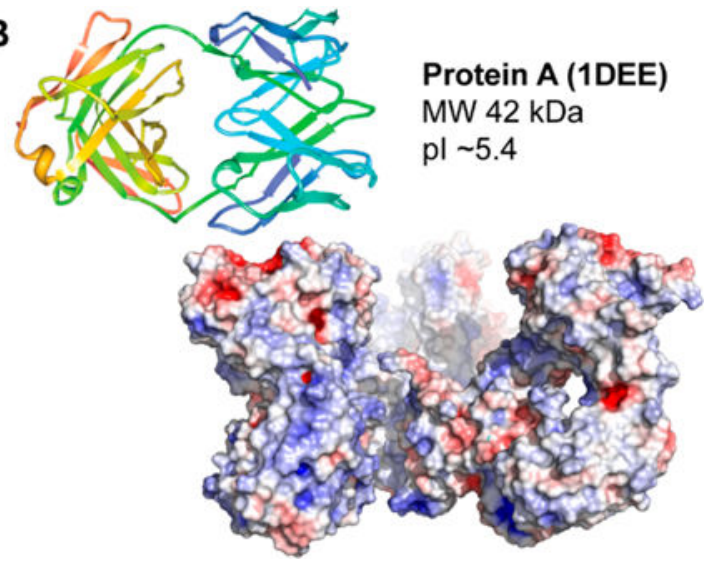

Figure 1.

(A) Structures of the lipids investigated based on varied charges. (B) Crystal structure and electrostatic potential map of protein A. Blue is indicative of negatively charged areas, while red is indicative of positively charged areas. 

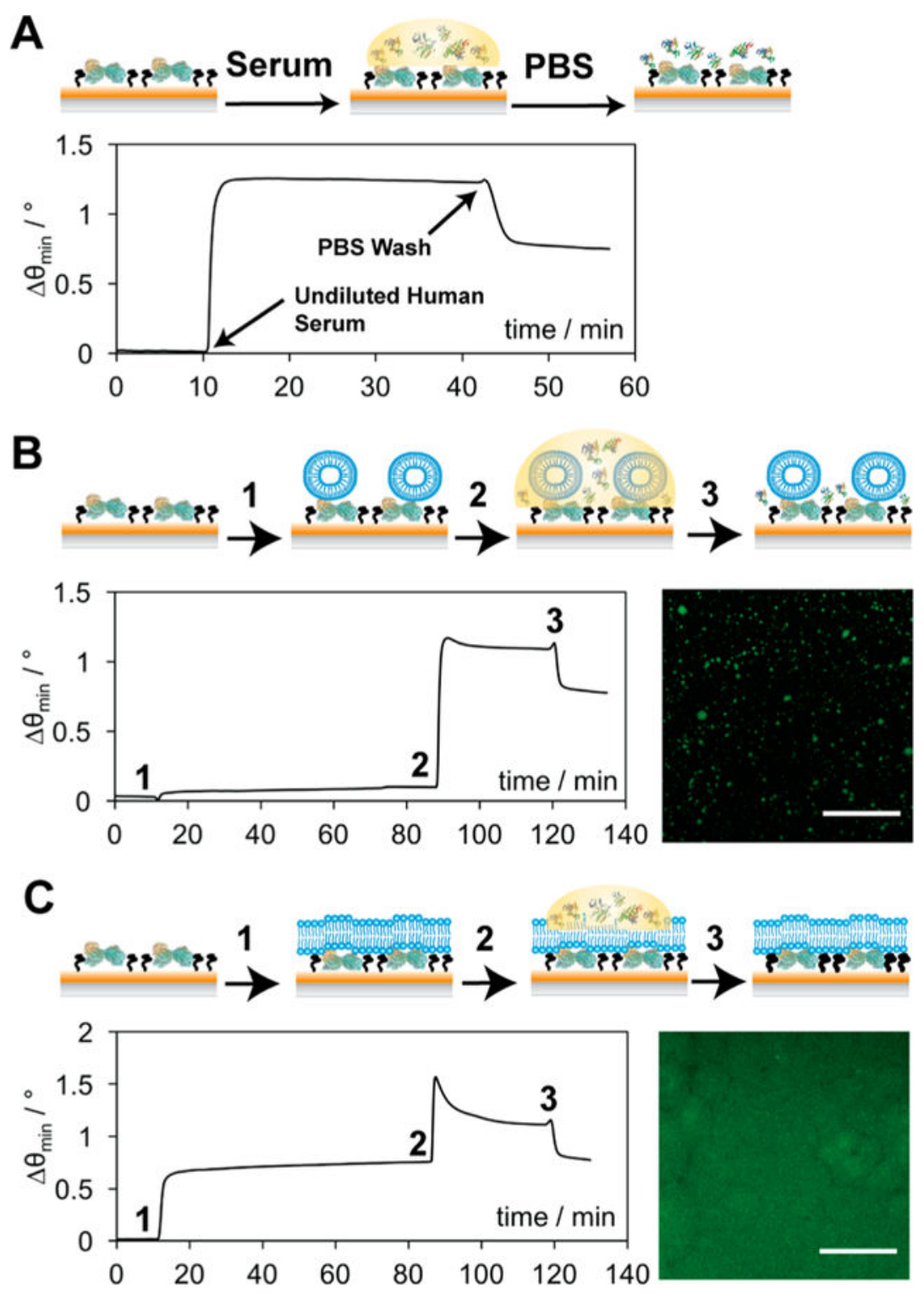

Figure 2.

Schematic representations and corresponding data for the addition of undiluted human serum to a protein A/MPO surface (A), POPC over protein A/MPO (B), and $\mathrm{EPC}^{+}$over protein A/MPO (C). Lipid vesicles (B and C) were injected (1) and incubated for $1 \mathrm{~h}$, before the addition of undiluted human serum (2) for $30 \mathrm{~min}$, followed by a PBS rinse (3) to remove any unbound components. Corresponding fluorescence micrographs depict distribution of POPC (B) and $\mathrm{EPC}^{+}(\mathrm{C})$, respectively, over protein A/MPO. Scale bars represent $30 \mu \mathrm{m}$. 

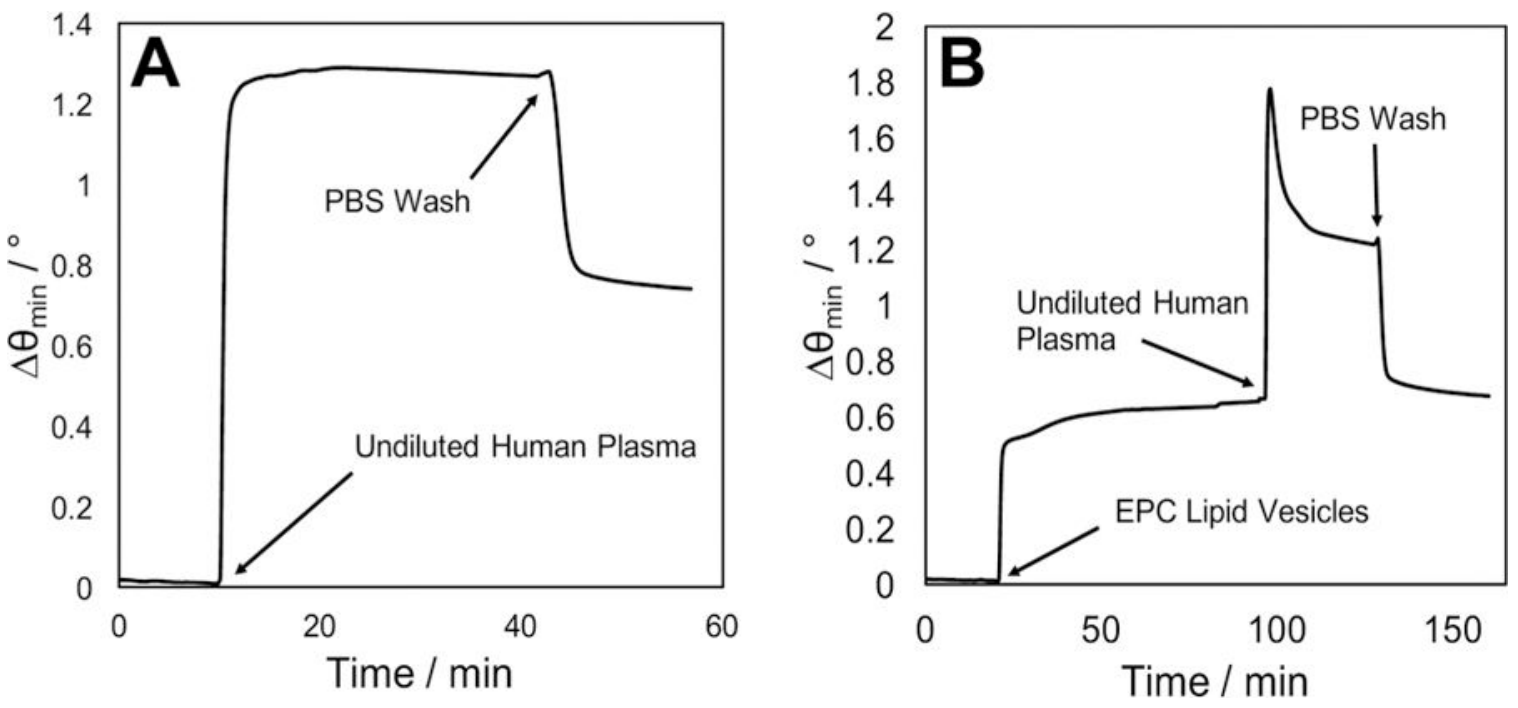

Figure 3.

Surface-plasmon resonance sensorgrams demonstrating the extent of nonspecific binding from undiluted human plasma injected over a protein A/MPO coated gold surface (A) and a protein/MPO surface coated with an $\mathrm{EPC}^{+}$lipid barrier (B). 

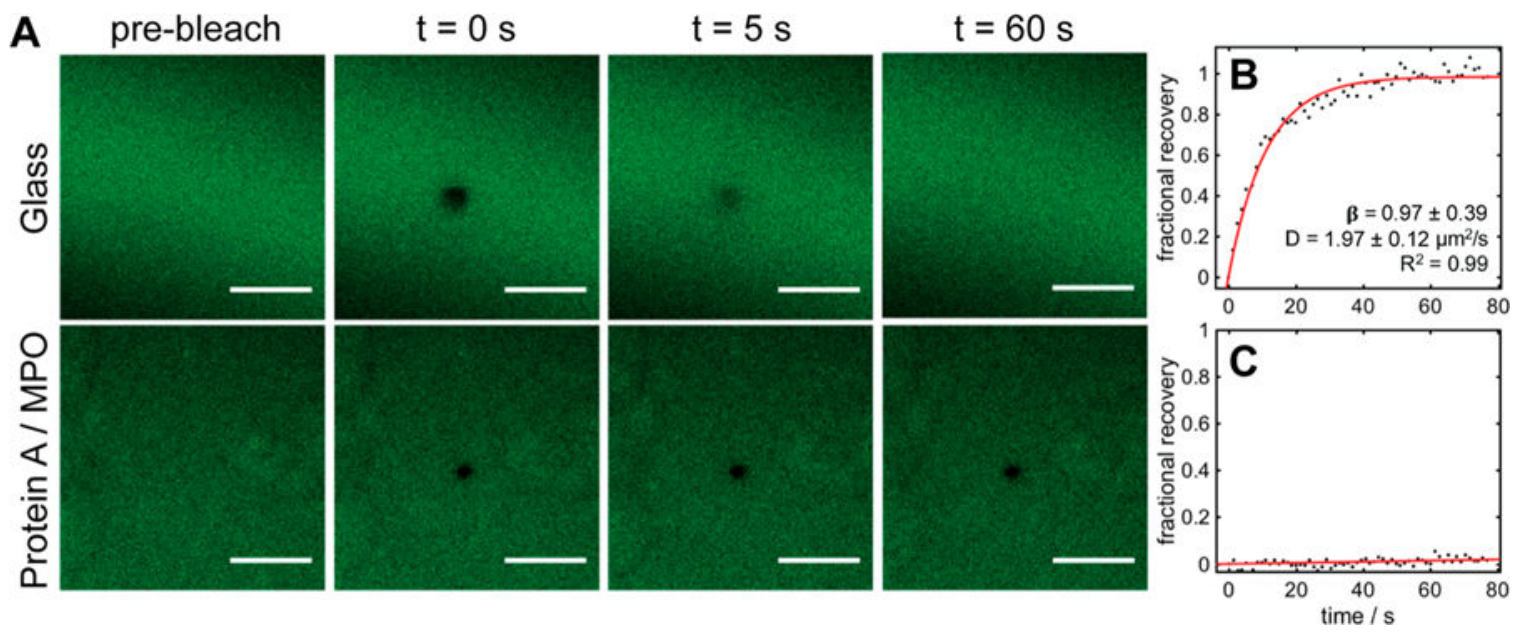

Figure 4.

Images depicting FRAP analysis of $\mathrm{EPC}^{+}$lipids formed over a glass coverslip and a protein A/MPO coated coverslip. (A) Fluorescence micrographs of photobleaching and recovery. Scale bars represent $30 \mu \mathrm{m}$. (B, C) Corresponding recovery data for $\mathrm{EPC}^{+}$over glass (B) and protein $\mathrm{A} / \mathrm{MPO}$ surface $(\mathrm{C})$. Error bars represent standard deviations from three replicate experiments. 

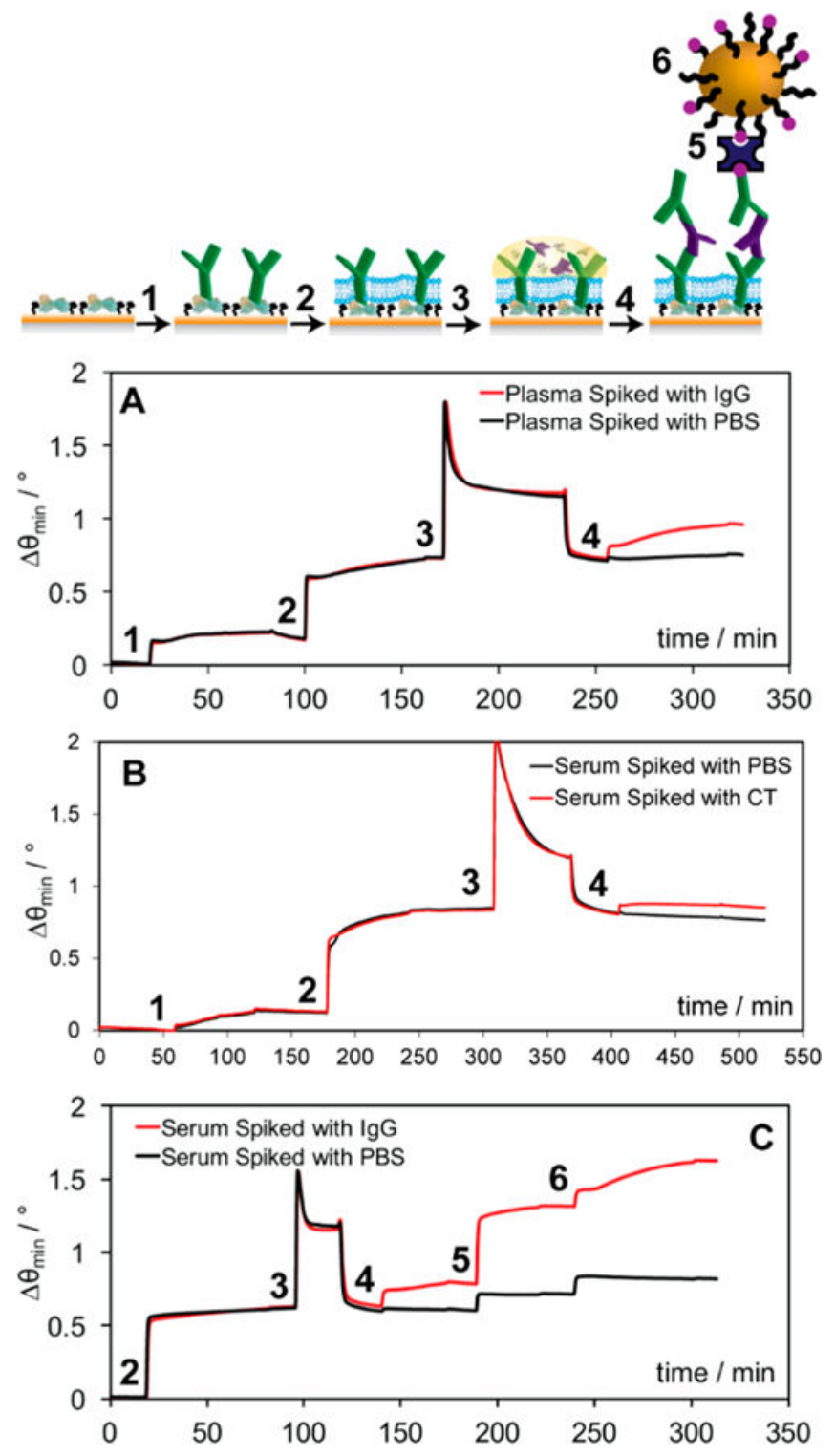

Figure 5.

Schematic and (A) sensorgram representing the detection of mouse $\operatorname{IgG}$ (red) in undiluted human plasma where the capture antibody is injected (1), followed by the EPC lipid vesicles (2), the plasma spiked with mouse $\operatorname{IgG}(3)$, and finally a detection antibody for enhancement (4). (B) Sensorgram representing the detection of CT (red) in undiluted human serum using a surface chemistry similar to that of the IgG, and the addition of serum spiked with CT (3), and finally a detection anti-CT for enhancement (4). (C) Sensorgram representing the detection of mouse IgG (red) in undiluted human serum where the capture antibody injected was applied offline and the EPC lipid vesicles were injected online (2), followed by the serum spiked with mouse $\operatorname{IgG}(3)$, a biotinylated detection antibody (4), streptavidin bridge (5), and biotin-labeled gold nanoparticles (6) for enhancement. 